\title{
The role of obesity in JAK2 V617F gene mutation among patients with recurrent pregnancy loss
}

\author{
Hala Awadallah*1, \\ Mai Shaker ${ }^{2}$, \\ Khaled Gaber ${ }^{2}$, \\ and \\ Khalda Amr ${ }^{3}$ \\ ${ }^{1}$ Institute of Environmental \\ Studies and Reasearch Ain Shams \\ University,Egypt. \\ ${ }^{2}$ Prenatal Diagnosis and Fetal \\ Medicine Department National \\ Research Centre, Medical \\ Molecular Genetics department \\ National Research Centre, Egypt. \\ ${ }^{3}$ Prenatal Diagnosis and Fetal \\ Medicine Department National \\ research Centre \\ ${ }^{*}$ Corresponding Author Email: \\ hala_awadalla@yahoo.com
}

\begin{abstract}
Maternal obesity is one of the factors that have a role in recurrent pregnancy loss (RPL). This research deals with fetal loss in obese pregnant women that might be due the mutation in Janus kinase 2 gene (V617F). The main purpose of this article is to explore the association of obesity with JAK2 V617F mutation in recurrent pregnancy loss. This study is carried out on 250 women, the case group with a history of recurrent pregnancy loss and a body mass index (BMI) $>24.9 \mathrm{~kg} / \mathrm{m}^{2}$. Control group consists of women with normal body mass index and have at least one live child and with no history of pregnancy loss. All subjects were investigated for the mutations by using the allele-specific multiplex PCR. Women in the study who were obese and tested positive for JAK2 $\mathrm{V} 617 \mathrm{~F}$ were $14 \% .9 .3 \%$ of patients in the case had a BMI with mean of $30.9 \pm 4.3$. In conclusion the study suggests a correlation between the increased risk for the occurrence of RPL in obese women and the investigated V617F mutation in the Jak2 gene exon 12, this research demonstrates the feasibility that obesity could be a modifiable risk factor for that somatic mutation.
\end{abstract}

Key words: RPL, Obesity, Gene (V617F)

\section{INTRODUCTION}

Recurrent pregnancy loss (RPL) was defined as two or more miscarriages. Antiphospholipid syndrome, uterine anomalies, and parental chromosomal abnormalities, particularly translocation and abnormal embryonic karyotype, are identifiable causes of RPL (SugiuraOgasawara, 2015)

About 1-3\% of women suffer from this medical condition during their reproductive period (Toth et al., 2010). Until know up to $50 \%$ of RPL cases the definite underlying cause or pathophysiological mechanisms is still not determined (Karvela et al., 2008).

There is a bad outcome that affects the mother and the offspring due to pre pregnancy maternal obesity for example diabetes, preeclampsia and thrombophlic disorders. Off spring of obese mothers are more liable to face difficulties during birth, macrosomia, and prenatal death (Nuthalapaty and Rouse, 2004). Gene mutations can be turned on by any change in the home environment and also the external environment in which human grow (Lobo, 2008).

Many hormones depend on their mechanisms on Jinas Kinas, JAK-signal transducers and activators of transcription STAT which greatly affects fat cell function. In Obesity leptin and IL-6 increase in obese women continually activating intracellular JAK-STA3. Leptin works mainly on central nervous system, IL-6 works on peripheral organs and in fact they can switch targets. Continuous JAK-STAT3 activation by leptin and IL-6 lead to the increased expression of the negative regulator SOCS3. SOCS3 in then have a negative feedback on leptin and IL-6 signaling regulating it plus antagonizing insulin action which leads to gaining more weight and insulin resistance (Wunderlich et al., 2013).

JAK2 is a tyrosine kinase which has a main role in signal 
transduction in many hematopoietic growth factor receptors. The (V617F) mutation is due to valine-tophenylalanine substitution at position 617 this mutation happened due to a gain-of-function mutation in the gene encoding the Janus kinase2 (JAK2), leading to continuous activation of tyrosine kinase and mutation of V617F. In the JH2 pseudo-kinase domain of JAK2 gene is responsible for offspring loss. This mutation was found in patients suffering from thrombocythemia. Thrombocythemia during pregnancy leads to sudden Pregnancy loss and decreased percentage in live rates (Randone et al., 2011; Elamgrabey and Badewy, 2012).

Some of the genetic mutations are acquired among a person's lifetime and are found only in some cells. These kind of changes, which are called somatic mutations in the JAK2 gene are correlated with essential thrombocythemia. (James, 2008).

Thrmobophilia leads to thrombosis of the uteroplacental circulation due to cascading that occurs in hemostatic response. Disturbance and decrease in placental perfusion may lead to recurrent pregnancy loss. (Lockwood and Wendel, 2011).

\section{MATERIALS AND METHODS}

This cross sectional study included 250 patients. The study group consists of 150 women with history of recurrent pregnancy loss for two consecutive times or more, aged (20-34) and having a body mass index of more than 24.9 $\mathrm{kg} / \mathrm{m}^{2}$. The control group consisted of 100 women having normal body mass index less than $24.9 \mathrm{~kg} / \mathrm{m}^{2}$ with at least one live child and no history of spontaneous miscarriages or uncomplicated pregnancy. All subjects were referred from the outpatient clinic of the Prenatal Diagnosis and Fetal Medicine Department, National Research Centre, Egypt. During the period from June 2014 to May 2015. An informed consent has been obtained from all patients and approved by the National Research Centre Ethical Committee.

Five $\mathrm{ml}$ venous blood samples were withdrawn from all subjects under complete aseptic conditions and collected in a polypropylene tube containing 0.5 M EDTA ( $\mathrm{pH} \mathrm{8.0)}$ to prevent clotting and nuclease activity.

\section{DNA extraction}

DNA genome was extracted from peripheral blood leukocytes of all candidates in the study using the QIAGEN DNA Extraction Kit (Qiagen, Germany).

\section{Detection for the V617F jak2 gene mutation}

V617F mutation is detected by using an allele-specific multiplex PCR having a one common reverse and other two separate forward primers was being used.150ng / $\mathrm{ml}$ of the DNA genome extract will act as a template in a the total volume of $25 \mu \mathrm{l}$ containing the following: $1.5 \mathrm{mmol} / \mathrm{L}$
$\mathrm{MgCl}_{2}, 20 \mathrm{pmol} / \mathrm{L}$ of each primer, $0.2 \mathrm{mmol} / \mathrm{L}$ dNTPs, and 1 $\mathrm{U}$ of Taq polymerase (Fermentas, Germany). Amplification using 40 cycles with an annealing temperature of $60^{\circ} \mathrm{C}$ was performed.

The target of the first forward primer is to amplify a 364bp fragment for both the mutant and the wild-type alleles but the second forward primer was put specifically to detect the presence of mutated allele and it has an extra mismatch near the $3^{\prime}$ end. The mutation produce a 203-bp product exclusively if V617F mutation is present (Horn et al., 2006).

\section{JAK2 Primer Sequences}

\begin{tabular}{|c|c|}
\hline & \\
\hline 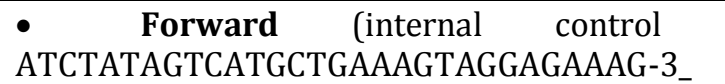 & \\
\hline $\begin{array}{lccc} & \text { Forward } & (\mathrm{V} 617 \mathrm{~F} & \text { specific)) } \\
\text { AGCATTTGGTTTAAATTATGGAGTATATT-3_' }\end{array}$ & $5-$ \\
\hline $\begin{array}{l}\text { • } \\
\text { CTGAATAGTCCTACAGTGTTTTCAGTTTCA- } \\
\end{array}$ & 5_- \\
\hline
\end{tabular}

Statistical analysis was carried out using Statistical Package for Social Sciences (SPSS) Statistical Software version 13 (SPSS Inc., Chicago, USA). Qualitative data are presented as frequencies and percentages, while quantitative data are presented as mean \pm standard. Chi-square and t test were used to calculate $\mathrm{p}$ values. $\mathrm{P}$ values less than 0.05 were considered as statistically significant.

\section{RESULTS}

Case group consisted of 150 women with history of RPL who were obese and tested for JAK2V617F mutation verses control group which had no history of RPL and had at least one living child. Having a live birth was reported in 64 patients in case group $(42.7 \%$ vs. $100 \%$ in control, $\mathrm{P}<$ $0.001)$. Jak2v617 mutation was found in 14 patient (9.3\%) in the case while no jak2v617f mutation was found among the control group, $(\mathrm{p}<0.0001)$. Consanguinity was positive in 82 cases and 13 of the controls $(57.4 \%$ vs. $13 \%$, p $<0.001)$. In the whole study population ( 250 women), women who had normal BMI were negative for jak mutation, while women who were obese and tested positive for JAK2 V617F mutation were 14. Giving a significant difference $\mathrm{p}<$ 0.001 . History of live birth were 64 out of 150 with a mean of $1.3 \pm 0.5$ (Table 1 ).

All patients included in the cases group had two or more RPL ranging from 2 to 11 abortions, their ages ranged from 20-35 years with a mean of 26.8 \pm 4.3 . Patients in case group were found to be obese with a mean BMI of $30.9 \pm 4.3$ vs. mean BMI in control group of $22.4 \pm 1.1$, ( $\mathrm{p}<0.001)$. Mean of history of live birth was $1.3 \pm 0.5$ in cases vs. $2.1 \pm 0.9$ in controls $(\mathrm{p}<0.001)$ (Table 2).

Women who had consanguineous marriages and tested positive for the mutation were nearly three quarters $(71.4 \%)$ and $36 \%$ of women who had consanguineous 
Table 1. Comparison between the case and control groups as regard the Consanguinity and JAK2 V617F mutation

\begin{tabular}{|c|c|c|c|c|c|c|c|c|}
\hline \multirow[b]{2}{*}{ Variables } & \multicolumn{2}{|c|}{ Case $(n=150)$} & \multicolumn{2}{|c|}{ Control $(n=100)$} & \multicolumn{2}{|c|}{ Total } & \multirow[b]{2}{*}{$\chi^{2}$} & \multirow[b]{2}{*}{$P$ value } \\
\hline & No. & $\%$ & No. & $\%$ & No. & $\%$ & & \\
\hline Consanguinity & & & & & 95 & 38 & 44.2 & $<0.001$ \\
\hline Yes & 82 & 54.7 & 13 & 13.0 & & & & \\
\hline No & 68 & 45.3 & 87 & 87.0 & 155 & 62 & & \\
\hline \multicolumn{9}{|l|}{ Live birth } \\
\hline Yes & 64 & 42.7 & 100 & 100.0 & 164 & 65.5 & 87.4 & $<0.001$ \\
\hline No & 86 & 57.3 & 0 & 0.0 & 86 & 34.5 & & \\
\hline \multicolumn{9}{|l|}{ JAK2 V617F } \\
\hline Positive & 14 & 9.3 & 0 & 0.0 & 14 & 5.6 & 9.9 & $<0.001$ \\
\hline Negative & 136 & 90.7 & 100 & 100.0 & 236 & 94.4 & & \\
\hline
\end{tabular}

Table 2. Comparison between the studied groups regarding the Age, live birth and Body Mass Index

\begin{tabular}{lllll}
\hline Variables & Case & Control & t & P \\
\hline Age & & & & \\
Range & $20-35$ & $20-31$ & 1.8 & 0.07 \\
Mean $\pm S D$ & $26.8 \pm 4.3$ & $25.9 \pm 3.1$ & & \\
Live birth & & & & \\
Range & $1.0-3.0$ & $1.0-4.0$ & 6.7 & $<0.001$ \\
Mean $\pm S D$ & $1.3 \pm 0.5$ & $2.1 \pm 0.9$ & & \\
BMI & & & & \\
Range & $26.4-43.2$ & $19.5-25.5$ & 19.3 & $<0.001$ \\
Mean $\pm S D$ & $30.9 \pm 4.3$ & $22.4 \pm 1.1$ & & \\
\hline
\end{tabular}

Table 3. Comparison between JAK2 V617F and obesity and Consanguinity

\begin{tabular}{|c|c|c|c|c|c|c|c|c|}
\hline \multirow{3}{*}{ Variables } & \multicolumn{4}{|c|}{ Jak } & \multicolumn{2}{|c|}{ Total } & \multirow[t]{3}{*}{$\chi^{2}$} & \multirow[t]{3}{*}{$\mathbf{P}$} \\
\hline & \multicolumn{2}{|c|}{ Positive } & \multicolumn{2}{|c|}{ negative } & \multirow[b]{2}{*}{ no } & \multirow[b]{2}{*}{$\%$} & & \\
\hline & no & $\%$ & & $\%$ & & & & \\
\hline \multicolumn{7}{|l|}{ Obesity } & \multirow[t]{3}{*}{9.88} & \multirow[t]{3}{*}{0.001} \\
\hline Normal & 0 & 0 & 100 & 42.4 & 100 & 40 & & \\
\hline Obese & 14 & 100 & 136 & 57.6 & 150 & 60 & & \\
\hline \multicolumn{5}{|l|}{ Consanguinity } & & & \multirow[t]{4}{*}{7.03} & \multirow[t]{4}{*}{0.001} \\
\hline Yes & 10 & 71.4 & 8.5 & 36 & 95 & 38 & & \\
\hline No & 4 & 28.6 & 151 & 64 & 155 & 62 & & \\
\hline Total & 14 & 100 & 236 & 100 & 250 & 100 & & \\
\hline
\end{tabular}

marriages they tested negative for the mutation. giving a significant difference $p<0.001$. (Table 3 ).

\section{DISCUSSION}

RPL is a traumatic event for the patient to go through and its challenging target for the clinician too. It is tough experience for the couple because they hardly get clear-cut answers for the repeated failure to maintain pregnancy. Nowadays, the list making the main etiologies for RPL has been changing .Recurrent pregnancy loss leaves a bad impact on patient psyche. It is also not one of the easy tasks to be dealt with in reproductive medicine. Recurrent pregnancy loss is an important reproductive health issue, affecting $2 \%-5 \%$ of couples. Common established causes include uterine anomalies, antiphospholipid syndrome, hormonal and metabolic disorders, and cytogenetic abnormalities. (El Hachem et al., 2017) It is recorded that the disorders which promote to venous thrombosis, are all named "thrombophilias," which have a role in the pathogenesis or the process of fetal loss. The great differences between theories as well as keeping in mind the correlation between such disorders and unexplained pregnancy loss suggests the presence of underlying risk modifiers (Mercier et al ., 2007).

The included women in the present study had at least one history of live birth, to rule out any anatomical factor that might be a cause for the repeated losses. In the current study, the participants had the same partner during their marital life to exclude paternal chromosomal abnormality that could affect the results. The presence of high incidence 
of thromboembolic attacks due to JAK2V617F gene mutation and pregnancy loss in obese women and a possible relationship between these parameters is a matter of concern. In this study women who were positive for JAK2V617F mutation in the case group represented $9.3 \%$ versus the control group who were negative for mutation $(\mathrm{p}<0.001) \quad$ Mercier al., (2007) supported this results that the mutation was present more frequently in patients with past history of pregnancy loss $(1.06 \%)$ than in control group $(0.20 \%)$. Also Melillo et al., (2009) stated that fetal loss encountered more in females with the JAK2 V617F mutation (mutated vs. unmutated: $36.0 \%$ vs. $8.3 \%, \mathrm{P}<0.037$ ), and this correlation was further confirmed by multivariate analysis (OR: 6.19; $95 \%$ CI: $1.17-32.61, \mathrm{P}<0.038$ ). In this study $54.7 \%$ of the case group of had consanguineous marriages while in the control group 13\% had consanguineous marriages giving a high significant difference $p$ value of $<0.001$. In another study conducted on the Turkish population Başaran et al., (2000) showed that $21.25 \%$ of the marriages were consanguineous marriages and there was an increased rates of abortions as well as prenatal fetal losses which support the results of tha current study.

The results of the present study showed that, the frequency of having at least one healthy live birth in the case group was $42.7 \%$ with a mean of $1.3 \pm 0.5$ while in the control all of them had a history of at least one live birth with a mean of $2.1 \pm 0.9$ with high significant difference of $\mathrm{p}<0.001$. In the case group of the current study the patients BMI had mean of $30.9 \pm 4.3$ while in the control group BMI had a mean of $22.4 \pm 1.1$ with high significant difference of $\mathrm{p}<0.001$, this is supported by a study made by SugiuraOgasawara, (2015) stating that Obesity may elevate the risk of pregnancy loss in sporadic pregnancies. Obese women with a body mass index (BMI) $>30 \mathrm{~kg} / \mathrm{m}^{2}$ can be an independent risk factor for having future pregnancy losses with odds ratio 1.7-3.5 in females having early RPL.

In the current study only 13 patients ( $9.6 \%$ ) in the case group experienced pregnancy loss after 12 weeks of gestation and while the rest of the case group including 14 patients who were positive for jak2v617f mutation experienced pregnancy loss before 12 weeks of gestation $(\mathrm{p}<0.0612)$. Dahabreh et al., (2009) stated that out of 389 cases, $92 \%$ faced early miscarriage and $14.1 \%$ suffered from late miscarriage while $6.1 \%$ had experienced both, Also Passamonti et al., (2007) reported that complications occurred in the mothers were $9 \%$, but the complications happened in the fetus were $40 \%$ out of the investigated 96 pregnancies. $27 \%$ out of 96 pregnancies had a first trimester abortion with only $4 \%$ had a second trimester abortion while the rest 3\% still birth and $4 \%$ growth retardation.

In conclusion, it is evident that this study has shown a possible association between the increased risk for the occurrence of RPL in obese women and the investigated V617F mutation in the Jak2 gene exon 12. Summing up the results, it can be concluded that obesity could be a risk modifier for that somatic mutation. Clearly, more research will be requires to prove that JAK2V617F could be predictor for recurrent pregnancy loss and that obesity is a modifiable risk factor. Further study on the effect of weight control programs on the prevention of further miscarriage in patients with RPL is desirable.

\section{Conflict of Interests}

The authors declare that there is no conflict of interests regarding the publication of this manuscript.

\section{REFERNCES}

Başaran N, Hassa H, Başaran A, Artan S, Stevenson JD, Sayli BS (1989):The effect of consanguinity on the reproductive wastage in the Turkish population. Clin Genet. 36(3):168-73.

Dahabreh IJ, Jones AV, Voulgarelis M, Giannouli S, Zoi C, Alafakis-Tzannatos C, Varla-Leftherioti M, Moutsopoulos HM, Loukopoulos D, Fotiou S, Cross NC, Zoi K (2009). No evidence for increased prevalence of JAK2 V617F in women with a history of recurrent miscarriage. Br. J. Haematol. 144(5):802-803.

El Hachem H, Crepaux V, May-Panloup P, Descamps P, Legendre G, Bouet PE (2017) Recurrent pregnancy loss: current perspectives Int J Womens Health. 17(9):331345.

EL-Maghraby S, Bedewy A (2012). Does JAK2 V617F Mutation in Egyptian Patients with First Episode Venous Thromboembolism Contribute to the Hypercoagulable State and Interact with other Thrombophilic Factors. Life Sci. J, 9 (2):12-16.

Horn T, Kremer M, Dechow T, Pfeifer M, Geist B, Perker M, Duyster J, Quintanilla L, Fend F (2006). Detection of the activatingJAK2 V617F mutation in paraffin embedded trephine bone marrowbiopsies of patients with chronic myeloproliferative diseases. J. Mol. Diagn.,8(3):299-304.

James C (2008). The JAK2V617F mutation in polycythemia vera and other myeloproliferative disorders: one mutation for three diseases? Hematology Am. Soc. Hematol. Educ. Program. :69-75.

Karvela M, Papadopoulou S, Tsaliki E, Konstantakou E, Hatzaki A, Florentin-Arar L and Lamnissou K (2008) .Endothelial nitric oxide synthase gene polymorphisms in recurrent spontaneous abortions. Arch Gynecol Obstet, 278 (2):349-335.

Lobo I (2008). Environmental influences on gene expression. Nature Education, 1(1):39.

Lockwood C, Wendel G (2011). Inherited thrombophilias in pregnancy. Obstet Gynecol,118 (2):730-740.

Melillo L, Tieghi A, Candoni A (2009). Outcome of 122pregnancies in essential thrombocythemia patients: A report from the Italian registry. Am. J. Hematol, 84 (2):636-640.

Mercier E, Lissalde-Lavigne G, Gris J (2007): JAK2 V617F Mutation in Unexplained Loss of First Pregnancy N. Engl. J. Med. 357(19):1984-1985. 
Nuthalapaty FS, Rouse DJ (2004). The impact of obesity on obstetrical practice and outcome. Clin Obstet Gynecol, 47 (4):898-913.

Passamonti F, Randi ML, Rumi E, Pungolino E, Elena C, Pietra D, Scapin M, Arcaini L, Tezza F, Moratti R, Pascutto C, Fabris F, Morra E, Cazzola M, Lazzarino M (2007). Increased risk of pregnancy complications in patients with essential thrombocythemia carrying the JAK2 V617F mutation. Blood, 110 (2):485-489.

Randone G, Coliazzo D, tiscia G, Vergura P, Cappucci F, Greco L, Margalione M, Martinellij P (2011). Impact of common thrombophilias and JAK2 V617F on pregnancy outcomes in unselected Italian women. Thromb Haemost, 9 (3): 496-501.

Sugiura-Ogasawara M (2015).Recurrent pregnancy loss and obesity,Best Pract Res. Clin Obstet Gynaecol, (4):489-97.

Toth B, Bastug M, Scholz C, Arck P, Schulze S, Kunze S, Friese K, Jeschke U (2008). Leptin and peroxisome proliferator-activated receptors: impact on normal and disturbed first trimester human pregnancy. Histol. Histopathol, 23(2): 1465-1475.

Wunderlich C, Hövelmeyer N and Wunderlich F (2013). Mechanisms of chronic JAK-STAT3-SOCS3 signaling in obesity. JAKSTAT , 2(2):1-7. 